\title{
RESEARCH ON THE IMMUNIZATION COVERAGE AND INFECTIOUS MORBIDITY RATES IN UKRAINE AND THE WHO EUROPEAN REGION
}

\author{
Alla Kotvitska, Olga Kononenko \\ Department of Social Pharmacy, National University of Pharmacy, Ukraine
}

\begin{abstract}
The article presents the results of a comparative analysis of the levels of immunization coverage against infectious diseases that can be prevented by routine vaccination, in Ukraine and in other countries in the European Region of WHO. It was found that starting from 2010 immunization coverage has decreased in Ukraine. None of the infectious nosology achieved the WHO recommended level of $95 \%$ immunization coverage in 2013.

The dynamics of infectious diseases of separate nosologies that could be prevented using vaccination in Ukraine and Europe during 2009-2013 were analyzed. It was found that the proportion of infectious morbidity of the population in Ukraine holds a significant share in the overall structure of infectious morbidity in Europe. There is a growing danger of highly contagious infections like measles, rubella, mumps, pertussis, diphtheria.
\end{abstract}

Keywords: infectious diseases, immunization coverage, preventive vaccination, The Global Vaccine Action Plan

\section{INTRODUCTION}

Nowadays, preventive vaccination is considered to be the achievement with the biggest impact for medicine for the last two centuries, leading to the most substantial influence on human health. For this period over 100 vaccine preparations have been created, and almost 40 only for last 10 years (1). More than 200 years have passed since the first vaccine against natural pox invention. Undoubtedly the biotechnological industry changes swiftly, new high-

\footnotetext{
Address for correspondence:

Olga Kononenko

National University of Pharmacy

Department of Social Pharmacy

4 Valentynivska st.,

61168 Kharkiv, Ukraine

e-mail:olga.kononenko.nfau@gmail.com
}

Received: December 4, 2015

Accepted: March 16, 2016 quality vaccines appear to be able to protect against several infections simultaneously.

Due to active immunization of the population in the whole world, it was possible to fully overcome such dangerous disease as smallpox, the complete liquidation of which was proclaimed by the Declaration of the 33d World Health Assembly in 1980.

Considerable success is also achieved against poliomyelitis. It was high-effective vaccines and preventive vaccination realization, based on planned and mass campaign of population immunization, that gave the possibility to proclaim the European region of the World Health Organization (Ukraine is a member) an area free of poliomyelitis on June 21, 2002.

Nowadays, preventive vaccination plays a leading role in the prevalence rate and death rate reduction in Ukrainian population caused by dangerous infectious nosologies marked by the National Calendar of Preventive Vaccination, namely: tuberculosis, 
measles, rubella, hepatitis $B$, pertussis, tetanus, epidemic parotitis, diphtheria, haemophilus influenzae disease and poliomyelitis (2).

According to the recommendations of the World Health Organization for the creation of a proper level of population immunity, the level of preventive vaccination on every recommended nosology must be $95 \%$. When only a sporadic prevalence of sickness arises, patients have an uncomplicated course of the disease and practically absence of lethality. This proves the high efficiency of immunization.

However, in recent years the level of preventive vaccination of the Ukrainian population remains low, because of a shortage of vaccines in clinics, population refusal of vaccination, presence of contradictions in some legal acts that regulate vaccinations $(3,4)$.

Taking into account the aforementioned, the analysis of the population's immunization level and the rate of infectious diseases in Ukraine, and a comparison of the indexes with the European ones became the aim of our research with a further determination of possible progress of infectious morbidity trends.

\section{MATERIALS AND METHODS}

Medical statistical data about the levels of infectious morbidity and immunization coverage from the sites of WHO and the Center for Health Statistics Ministry of Health of Ukraine were the objects of the research. The research graphic method was used for presentation of the statistical data and schematic representation of the results. The method of scientific generalization was used to show conclusions and possible trends in the development of the epidemic process in the future.

\section{RESULTS AND DISCUSSION}

The first stage of our research was a comparison of the percentage of the population involved in preventive vaccination in children under the age of 1 in Ukraine and in 53 countries of the European region (WHO) and their comparison with the indexes recommended and pre-arranged by WHO.

The primary health care strategic purposes and directions of activity concerning planned preventive vaccination of the population in the European countries are registered in the The Global Vaccine Action
Plan. It was ratified on May 26, 2012 at the 65th session of the World Health Assembly. The 2011-2020 period is proclaimed The Decade of Vaccines by the marked document.

According to The Global Vaccine Action Plan there are six major goals in immunization, deadlines of which are approaching or missed, namely:

* national vaccination coverage of $90 \%$ with the third dose of DTP vaccine in all countries;

* the introduction in national immunization plans of at least one new vaccine that is not widely used in 90 low- and middle-income countries by 2015;

* the elimination of new poliomyelitis cases after 2014;

* the liquidation of tetanus in mothers and newborns in the world by the end of 2015;

* the elimination of measles in the three regions of WHO by the end of 2015, namely: in the Eastern Mediterranean, the European Region, and the Western Region of the Pacific ocean;

* the elimination of rubella in the European Region of WHO by the end of 2015 (5).

Today the WHO experts group on immunization emphasizes the significant delay in the schedule to achieve these goals.

The WHO Regional Office for Europe has developed the European Vaccine Action Plan 20152020 (EVAP) for additions, interpretation and adaptation on a regional level (6).

In Ukraine, a document, intended to implement the goals of the Global Vaccine Action Plan at a national level, is the Law of Ukraine "On Approval of the National Immunization Program and protection from infectious diseases in 2009-2015" adopted on October 21, 2009 (7).

The results of the analysis of the immunization coverage of children under 1 year of age, considered more susceptible to infectious diseases, show there is a sharp fall in Ukraine since 2010. It was less than $50 \%$ for some infections and that fact is a critical indicator. Especially difficult was the situation in 2013, not even one of the infectious nosologies achieved the WHO recommended level of $95 \%$ immunization coverage (8). 
Alla Kotvitska, Olga Kononenko

In particular, only $24 \%$ of children got hepatitis $B$ vaccination.

Measles liquidation is an extremely difficult task. It requires $95 \%$ of vaccination coverage in each region. This virus circulation can spread if even one region has lower immunization. The situation is the same with rubella. For the prevention of these infections there is a combined vaccine against measles, mumps and rubella in Ukraine but this vaccination coverage is extremely low (only $39 \%$ in 2013) (Table 1). period $2009-2013$. Thus, $80 \%$ of children received tuberculosis vaccine in 2013 .

If we follow the European immunization coverage dynamic indexes, we can say that in the most infectious nosologies they meet the The World Health Organization requirements. Only the Haemophilus influenzae disease and hepatitis B vaccination coverage are not high enough $-83 \%$ and $81 \%$, respectively, but these indexes are not considered to be critical parameters by WHO experts.

Table 1. Comparative analysis of the immunization coverage of children under 1 year of age in Ukraine and in the WHO European Region during 2009-2013

\begin{tabular}{|c|c|c|c|c|c|c|c|c|c|c|c|c|}
\hline \multirow[b]{2}{*}{ Year } & \multicolumn{6}{|c|}{ Ukraine, \% } & \multicolumn{6}{|c|}{ WHO European Region, \% } \\
\hline & 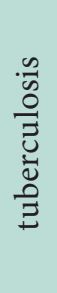 & 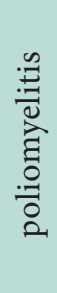 & 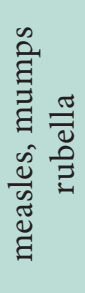 & 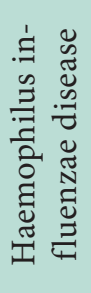 & 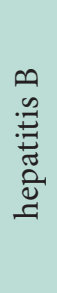 & 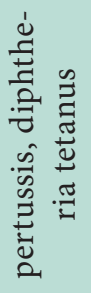 & 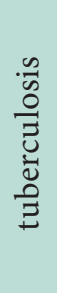 & 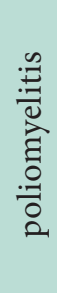 & 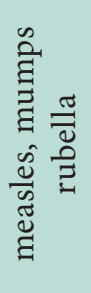 & 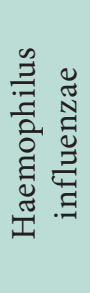 & 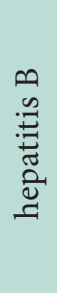 & 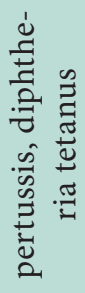 \\
\hline 2009 & 96 & 74 & 75 & 66 & 68 & 71 & 94 & 95 & 94 & 72 & 77 & 95 \\
\hline 2010 & 92 & 57 & 56 & 51 & 48 & 52 & 95 & 95 & 93 & 74 & 78 & 94 \\
\hline 2011 & 90 & 58 & 67 & 26 & 21 & 50 & 94 & 95 & 94 & 77 & 78 & 94 \\
\hline 2012 & 95 & 74 & 79 & 83 & 46 & 76 & 95 & 96 & 95 & 83 & 79 & 96 \\
\hline 2013 & 80 & 62 & 39 & 39 & 24 & 60 & 95 & 96 & 95 & 83 & 81 & 96 \\
\hline
\end{tabular}

One of The Global Vaccine Action Plan goals is to achieve a $90 \%$ level of immunization coverage with the third dose of DPT vaccine (pertussis, diphtheria and tetanus) by 2015. The high level of DPT 3 vaccination coverage shows that the country has an effective system immunization planning. As shown in Table 1, the immunization coverage indicated that the vaccination in Ukraine is significantly behind this indicator. It was only 60\% in 2013.

As for poliomyelitis, the cases were not registered during the period under review in Ukraine. However, in 2014 the risk of poliomyelitis was declared an international problem. So, the too low poliomyelitis immunization coverage in Ukraine (62\%) creates a significant section of non-immunized people and a danger of its appearance and distribution.

Vaccination against tuberculosis was the measure carried out in its fullest in Ukraine during the
Taking into account very low immunization coverage level of Ukrainian children, the next stage of our study was to analyze the dynamics of infectious diseases, of separate nosologies, that could be prevented using vaccination in Ukraine and Europe during 2009-2013.

The most dangerous infant infectious diseases, which despite significant advances in vaccination, today are still continuing to make a significant contribution to infant sickness rate and are of concern to WHO experts are: measles, rubella, mumps, pertussis and diphtheria (9). We have analyzed the sickness rate dynamics.

In recent years, the measles sickness rate has been increasing in the WHO European Region. In 2013 there were almost 30 thousand cases (10).

The Ukrainian National Program of Immunization and Infectious Diseases Protection in 20092015 had planned to bring the measles, mumps and 
pertussis occurrence to less than 1 per 100 thousand by 2010. These indexes are much higher than planned (Fig 1, 2, 3).

WHO experts stressed on the dangerous situation concerning pertussis in the European region. Despite significant advances in the fight against this infection, there are some pertussis cases. In 2012 the situation with the disease was especially threatening. 5.01 per 100 thousand cases were registered in Ukraine and 6.36 cases per 100 thousand - in the entire WHO European Region (Fig. 3).

The Global Vaccine Action Plan and the $\mathrm{Na}-$ tional Immunization Program had planned complete cessation of the measles and rubella virus transmission in the European region and in Ukraine by the end of 2015, but following the dynamics of these diseases, there is a significant backlog of the set goals (Fig. 1, 4).

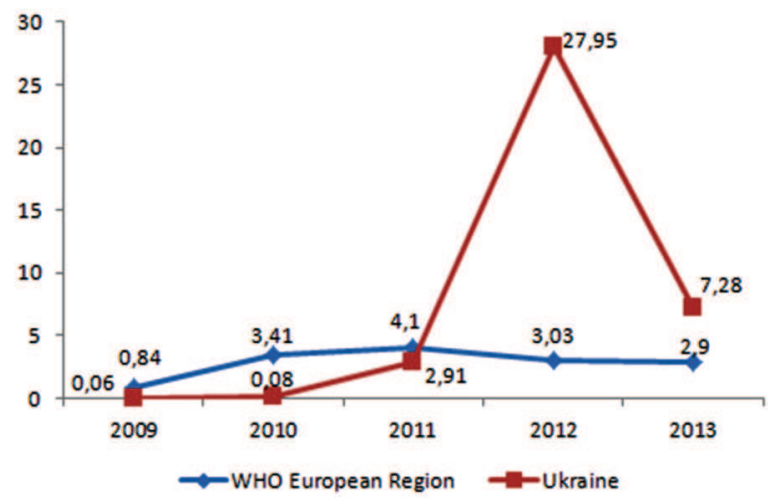

Figure 1. Dynamics of measles cases in Ukraine and in the WHO European Region during 2009-2013 (per 100 thousand population)

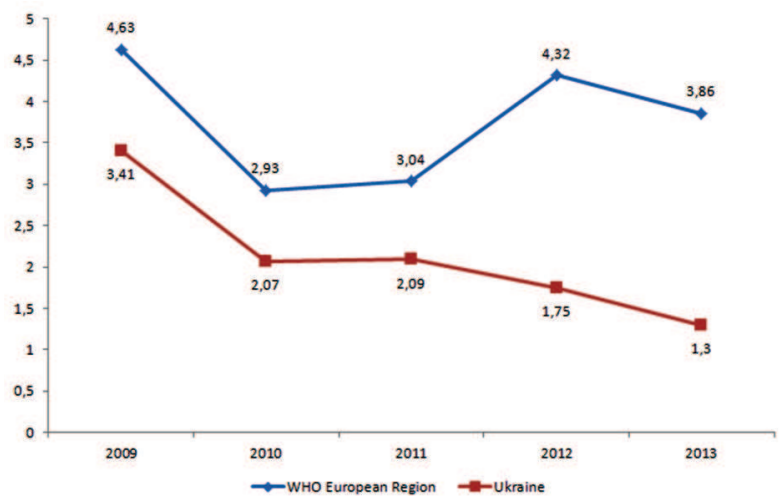

Figure 2. Dynamics of mumps cases in Ukraine and in the WHO European Region during 2009-2013 (per 100 thousand population)

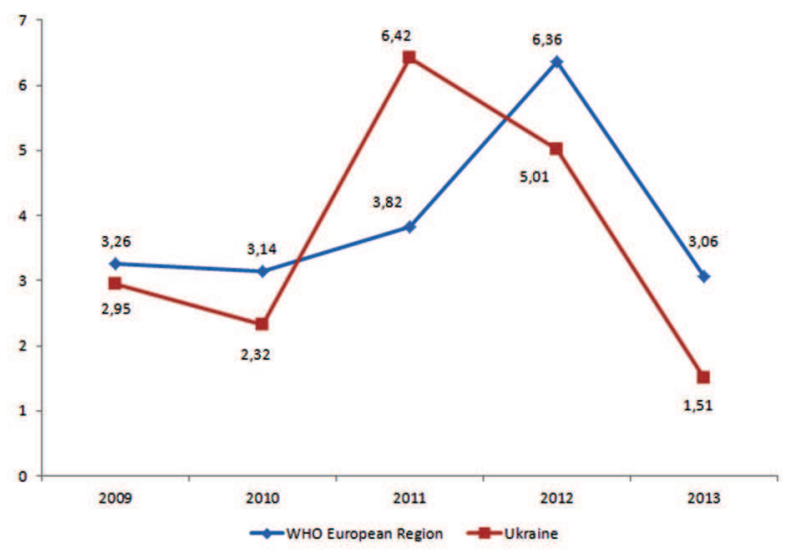

Figure 3. Dynamics of pertussis cases in Ukraine and in the WHO European Region during 2009-2013 (per 100 thousand population)

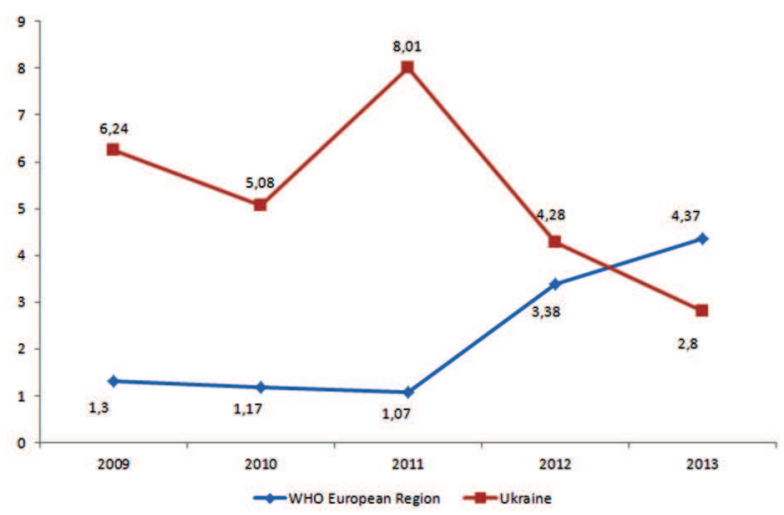

Figure 4. Dynamics of rubella cases in Ukraine and in the WHO European Region during 2009-2013 (per 100 thousand population)

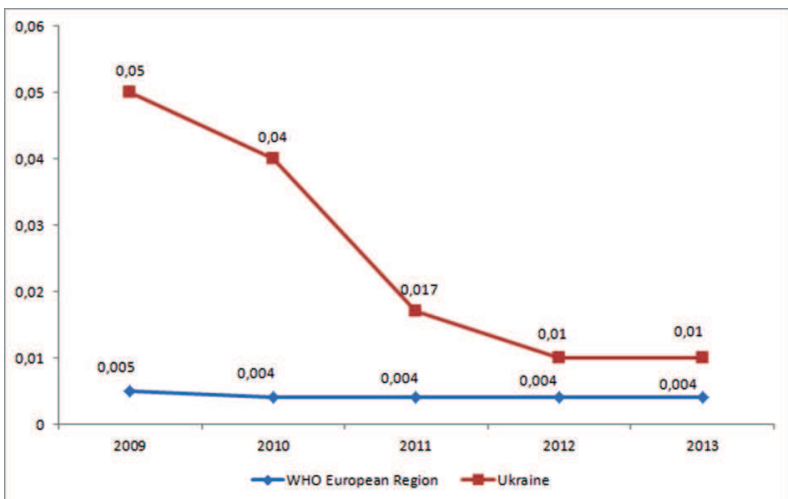

Figure 5. Dynamics of diphtheria cases in Ukraine and in the WHO European Region during 2009-2013 (per 100 thousand population)

The feature of the dynamics of the epidemic process for measles and rubella in Ukraine shows that the frequency of morbidity rises every $4-5$ years, 
Alla Kotvitska, Olga Kononenko

which is a significant concern, given the critically low level of the immunization coverage for the pe$\operatorname{riod}(11)$.

One of the goals of the aforementioned documents was to bring the cases of diphtheria to a rate of less than 0.1 per 100 thousand population. This goal was achieved both in Ukraine and in the European region (Fig. 5).

So, today there is a tendency to reduce the incidence of infection, managed by means of specific immunization. The high levels of immunization in 2009 lead to such reduction. However, temporarily,

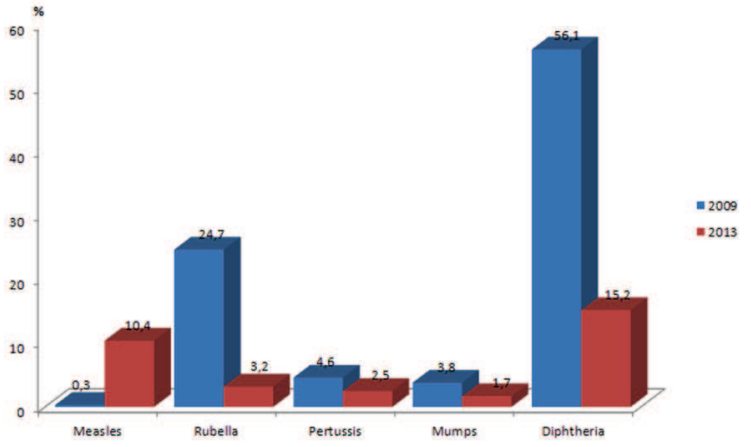

Figure 6. Analysis of the morbidity proportion of Ukraine in the WHO European Region morbidity structure for certain infectious diseases there are rare infectious diseases cases because of a significant decline in immunization since 2010 and a gradual fall of population immunity.

Based on the study of growth parameters for certain infectious disease results, it's found extremely rapid growth of highly contagious disease such as measles rate in Ukraine. Thus, in 2013 this indicator exceeded the same indicator in 2009, in 138 times because of morbidity sharp flash. For the rest of the analyzed infections it was, conversely, a decrease in morbidity growth rate. The highest it was in diphtheria which cases decreased by $78 \%$.

As for the WHO European Region it has registered an increase in the incidence of measles and rubella -4.2 and 3.4 times, respectively. For the rest of the infections a slight decrease in morbidity is observed (Table 2).

If we analyze Ukraine's morbidity proportion in Europe, it can be argued that it is rather high in some infections. In particular, the number of measles cases in Ukraine in 2013 accounted for 10.4\% of all cases in the European region, this is significantly higher than in 2009 (0.3\%). The incidence of diphtheria proportion is rather high: in 2009 it was $56.1 \%$; in 2013 this index dropped to $15.2 \%$. In 2009 there was

Table 2. Some infectious disease dynamics in Ukraine and in the WHO European Region during 2009-2013

\begin{tabular}{|c|c|c|c|c|c|}
\hline \multirow{3}{*}{$\begin{array}{l}\text { Nosological } \\
\text { forms }\end{array}$} & \multicolumn{4}{|c|}{ Number of reported cases } & \multirow[b]{3}{*}{ Growth rates, $\%$} \\
\hline & \multicolumn{2}{|c|}{2009} & \multicolumn{2}{|c|}{2013} & \\
\hline & $\begin{array}{c}\text { The absolute } \\
\text { number }\end{array}$ & $\begin{array}{l}\text { At } 100 \\
\text { thousand. } \\
\text { population }\end{array}$ & $\begin{array}{c}\text { The absolute } \\
\text { number }\end{array}$ & $\begin{array}{l}\text { At } 100 \\
\text { thousand. } \\
\text { population }\end{array}$ & \\
\hline \multicolumn{6}{|l|}{ Ukraine } \\
\hline measles & 24 & 0.06 & 3308 & 7.28 & 13683.3 \\
\hline rubella & 2868 & 6.24 & 1270 & 2.8 & -55.7 \\
\hline pertussis & 1356 & 2.95 & 685 & 1.51 & -49.5 \\
\hline mumps & 1567 & 3.41 & 590 & 1.3 & -62.3 \\
\hline diphtheria & 23 & 0.05 & 5 & 0.01 & -78.3 \\
\hline \multicolumn{6}{|c|}{ WHO European Region } \\
\hline measles & 7499 & 0.84 & 31685 & 2.9 & 322.5 \\
\hline rubella & 11623 & 1.3 & 39367 & 4.37 & 238.7 \\
\hline pertussis & 29229 & 3.26 & 27741 & 3.06 & -5.1 \\
\hline mumps & 41448 & 4.63 & 35050 & 3.86 & -15.4 \\
\hline diphtheria & 41 & 0.005 & 33 & 0.004 & -19.5 \\
\hline
\end{tabular}


a significant rubella incidence proportion $-24.7 \%$, in comparison to $3.2 \%$ in 2013 (12).

Thus, Ukraine has a stable trend of infections cases: measles, rubella and diphtheria that can lead to an increase in morbidity and even to an epidemic in low immunization coverage conditions.

\section{CONCLUSIONS}

1. Sufficiently high level of preventive vaccination coverage in Ukraine before 2009 contributed to a high level of population immunity that allowed the inhibition of the growth and spread of infectious diseases due to immunization during a certain period of time.

2. Increased number of disease cases, while the catastrophic decrease of preventive vaccination in recent years (especially during 20102012), indicate a gradual accumulation of susceptible persons in the population.

3. There is a growing danger of high-contagious infections like measles, rubella, mumps, pertussis, diphtheria and the immunization coverage is critically low in recent years. The fact is that Ukraine's population morbidity proportion in the structure of the WHO European Region morbidity is rather large despite the high level of preventive vaccination coverage.

4. In order to create and to keep a stable epidemic situation in Ukraine when it comes to infections it is necessary to ensure the sufficient immunization coverage recommended by WHO which would be included in the National Program on Immunization (not less than 95\%). This is possible only if we completely meet the needs of health care institutions in regard to vaccinations and the uninterrupted and regular delivery of immunological medicaments to all regions.

\section{REFERENCES}

1. Grigorov E.E., Lebanova H.V., Belcheva V.I. Launching of a medico-social model of ideally vaccinated person in Bulgaria. Health Economics and Management, 2014, 1: 64-68.

2. Law of Ukraine «On population protection against infectious diseases» 06.04.2000 № 1645-III (current edition of 12.05.2012, the base 5460-17) (http://zakon4.rada.gov.ua/laws/show/1645 -14).

3. Kotvitska A.A., Kononenko O.V., Kubaryeva I.V. Iinfectious morbidity in Ukraine as an important medical and social problem. Ukrainian theoretical and practical Internet conference materials «Social Pharmacy in Ukraine: state, problems and perspectives», 3-8 April 2013, Kharkiv: 196 - 197.

4. Kramareva S.A., Vyhovskaya L.V., Zakordonets A.V., Voronov A.A. Infection and preventive immunization. Modern infection. Kyiv, 2009, 3/4.: 11-17.

5. Global vaccine action plan 2011-2020. Copenhagen: World Health Organization, 2013: 77 p.

6. Kotvitska A.A., Kononenko O.V., Kubaryeva I.V. Scientific analysis of modern approaches to immunization in the world. Current Issues pharmaceutical and medical science and practice, 2014, 3: 72 -76 .

7. Law of Ukraine «On Approval of the National Immunization Program and protection from infectious diseases in 2009-2015» adopted 21.10.2009 № 1658-VI (http://zakon2.rada.gov.ua / laws / show / 1658-17).

8. Medical and demographic situation and highlights health care in region: results of work in 2011. Kyiv, Health Ministry of Ukraine, 2012: 192 p.

9. Mnushko Z.M., Sofronova I.V. Immunization organizing abroad. Clinical Pharmacy. 1998, Vol.2 (1): $63-67$.

10. Centralized Information System for Infectious Diseases (CISID) [online database]. Copenhagen: WHO Regional Office for Europe; (http://www.euroflu.org/index.php, on July 7, 2014).

11. National Report on the technological safety state in Ukraine in 2012. Kyiv, Health Ministry of Ukraine, 2013: 56 - 80.

12. WHO vaccine-preventable disease monitoring system, in 2013 global summary. Global and regional immunization profile: European Region. Geneva: World Health Organization; 2013 (http://apps.who. int/immunization_monitoring/data/gs_eurprofile.pdf, accessed 24 July 2014). 